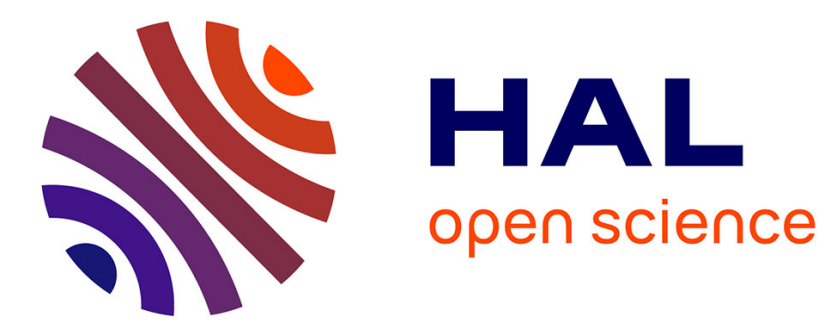

\title{
The role of the facilitator during digital creative sessions
}

Nawel Takouachet, Jérémy Legardeur, Iban Lizarralde

\section{To cite this version:}

Nawel Takouachet, Jérémy Legardeur, Iban Lizarralde. The role of the facilitator during digital creative sessions. Conférence Ergo'IA (Ergonomie \& Informatique Avancée), Oct 2014, Bidart / Biarritz, France. pp.20 - 23, 10.1145/2671470.2671473 . hal-01095081

\section{HAL Id: hal-01095081 \\ https://hal.science/hal-01095081}

Submitted on 15 Dec 2014

HAL is a multi-disciplinary open access archive for the deposit and dissemination of scientific research documents, whether they are published or not. The documents may come from teaching and research institutions in France or abroad, or from public or private research centers.
L'archive ouverte pluridisciplinaire HAL, est destinée au dépôt et à la diffusion de documents scientifiques de niveau recherche, publiés ou non, émanant des établissements d'enseignement et de recherche français ou étrangers, des laboratoires publics ou privés. 


\section{The Role of the Facilitator during Digital Creative Sessions}

\author{
Nawel Takouachet \\ ESTIA, 64210 Bidart, France \\ n.takouachet@estia.fr
}

\author{
Jérémy Legardeur \\ ESTIA, 64210 Bidart, France \\ IMS, 33405 Talence, France \\ j.legardeur@estia.fr
}

\author{
Iban Lizarralde \\ ESTIA, 64210 Bidart, France \\ i.lizarralde@estia.fr
}

\begin{abstract}
RESUME
L'animation des sessions de créativité permet d'améliorer l'efficacité d'un groupe pour la résolution de problèmes, la recherche de nouveaux concepts ou de solutions innovantes. Ce papier aborde le rôle de l'animateur pendant une session de créativité dans un environnement numérique. Nous évaluons les logiciels collaboratifs existants qui utilisent la métaphore du Post-it ${ }^{\circledR}$ et nous montrons que ces applications ont été conçues pour être utilisées sans forcément tenir compte de la présence d'un animateur. Ils offrent cependant un ensemble de fonctions qui sont pertinentes pour le groupe et ses individus. En nous basant sur ces constatations, nous proposons un ensemble de fonctionnalités principales pour intégrer pleinement le rôle de l'animateur aux applications digitales lors des sessions de créativité.
\end{abstract}

\section{Mots Clés}

Digital creativity session; Software for collaborative creativity; Creativity facilitator.

\section{ABSTRACT}

Facilitation is proved to improve group problem-solving effectiveness, research new concepts and innovative solutions. This paper addresses facilitation role during a creative session in the digital environment. We evaluate existing collaborative software based on the metaphor of the sticky note and we show that they are designed for use without necessarily taking into account the presence of a facilitator. They offer however, a set of functions that are relevant to the group and its individuals. According to our findings, we suggest a set of principal features to fully integrate the role of the facilitator into digital creativity sessions.

\section{ACM Classification Keywords}

H.5.2: User Interfaces, H.5.3: Group and Organization

\section{INTRODUCTION}

Creativity engages the mind ability to bring new relevant insights to solve a challenge. This process is indeed a prerequisite driver of the innovation, which is the action of turning the creative ideas into real products and services.

Increasingly, companies invest and place value on creative thinking and innovation to face rapid advances and increasing competition in new business, strategic, technological and human resources development. Companies aim to boost their employee's creativity for reaching successful outcomes and ensuring sustainability of their activities.

There are numerous creative techniques and most of them are based on the brainstorming principle developed by Alex Osborn [16]. Osborn with his colleagues developed brainstorming based methods such as SCAMPER [8], Creative Solving Problem [17]. These techniques can be applied during creative session to help generate order and prioritize information, combine and chunk ideas, propose solutions and find alternative. One of the wide popular tools that can be easily adapted and used with different creative techniques is sticky notes. Ideas are recorded on small colored paper that can be easily moved and then used for other tools such as theming and linking.

Today, and thanks to technological advances, the principle of sticky note is transposed to graphical interfaces with multiple software applications, allowing low costs solutions with new useful features such as portability, collaborative work on distant sites, flexible organization, backups and restores steps. Nevertheless, despite of these multitude of available digital applications, the use of paper-based sticky notes during creative session, especially professional consulting services continued to be dominant and far from being dwindled.

In this paper, we attempt to understand why digital applications for creative session have difficulty to assert as an alternative to paper-based conventional methods? We present a review of existing software for creative session based on sticky notes and similar component. We highlight the fact that these applications do not take into account the specific role of the facilitator. Indeed, the facilitator is an important active member of the creative meeting, able to understand the group dynamics and specialized in leading and pushing creativity from a group. As a matter of fact, if the facilitator is successful, the objective of the creativity session will be achieved: 
solutions will be produced, understood and agreed by all participants.

Therefore, it is essential that digital applications for creative session integrate facilitations steps and functions. To this end, we propose useful guidelines that help to design embedded facilitation-oriented features in digital creativity sessions.

\section{FACILITATOR ROLE}

Generally, group members are not trained in working group processes. The facilitator is a group process trainer, he is charged to help the group to solve problems and take process-related decisions [20, 19, 6, 18].

The facilitator understands and involves the group dynamics to guide and stimulate interaction between the participants. He seeks to keep the creativity process moving forward and ensure reaching the session outcomes with clear thinking and good global participation. Blumberg and Golembiewski [5] described a list of the facilitator' functions, as follows:

1. Creates situations conducive to learning.

2. Establishes a model of behavior.

3. Provides new values in process.

4. Facilitates the flow of information.

5. Participates as an expert.

6. Protects participants from unnecessary stress and attack.

7. Confronts the group regarding its processes.

During the creative process, the facilitator practices different creativity techniques that are appropriate to the context, the group nature and the problem to resolve.

\section{COLLABORATIVE TAKING NOTES SOFTWARE}

We present in this section an overview of existing software that support collaborative creativity thinking and offered the possibility to generating and structuring ideas using sticky notes or similar component. We include in this study digital applications that cover colocated and remote collaborative work. We are interested in how these applications take into account the role of the facilitator during the creative process. Indeed, we focus on useful features and functions during creativity sessions, in particular those requested in the facilitation mode.

Evernote [Erreur ! Source du renvoi introuvable.] is a powerful application widely used by the general public. It allows taking notes, photos, create to-do lists, record audio reminders and search notes. It synchronizes all notes on all the computers, phones and tablets. Nevertheless, Evernote does not directly support realtime collaboration; it has to be used with LiveMinutes [2], a web-based application that allows users to collaborate on their notes in real time and simultaneously synchronized with Evernote. Microsoft Office OnNote
[3] offers the same services as its competitor Evernote. It has to be linked with Outlook 2013 to let a user create a shared workspace and made edits in real-time by all the invited participants.

However, even by integrating the collaborative aspect, Evernote and OneNote are principally note taking software and do not implement specific functions for creativity sessions.

Kalemmer et al. [15] developed Designers' Outpost, a tangible user interface that combines physical and electronic representations of sticky notes. Users can write on a paper sticky note with a standard pen and place it on the electronic board. The interface integrates a computer vision component for capturing and digitalizing the physical sticky notes. Users can link sticky notes by drawing a line from one note to another with a stylus; when a sticky note is moved on the board, all its associated links follow. Everitt et al. [9] extended the Designers' Outpost to support remote collaboration on distributed media spaces.

Note that authors have observed two styles of interacting with the board: the facilitator and the open board style. In the facilitator style, one person chairs the board and engages discussion between participants. Progressively, as concepts arise, the facilitator links notes together and creates notes that synthesize the discussion content. In the open board style, however, everyone gets to actively create notes and place it on the board.

Hilliges and al. [13] have designed a brainstorming application that uses an interactive table and a large wall display. Authors investigated how collaborative creativity can be supported in digital environment while maintaining face-to-face communication. They developed pen-based user interfaces and focused design on handwriting and fluid gestures interaction. Participants can create a sticky note by simply drawing a square on the table surface. During divergent thinking step, the participants switch on the board and they can move and reorganize sticky notes. The application implements a clustering function which is largely used by the facilitator during the creative session. It allows creating clusters by simply drawing a circle around some sticky notes. Clusters are merged by dragging them close together and can be connected to each other or to a single sticky note by drawing a line connecting borders.

Tele-Board $[10,11]$ is a remote collaboration web that supports idea generating and structuring. The system integrates a video conference feature to synchronous transparent whiteboard overlay. Two whiteboards are installed on two remote sites. Gestures and facial expression of each participant acting on one of the two whiteboards are displayed as transparency on the other whiteboard. In this way, the group member are immersed with a co-presence feeling and take thus advantage of the benefits of face to face communication. 
Tele-board implements a large number of features that are highly requested in the facilitator mode during the session of creativity. It allows forming clusters or even hierarchical structures that can be exported in mind map format. In addition, creativity templates can be loaded as background pictures and used to group and classify the notes generated by participants. Furthermore, the TeleBoard system offers the possibility to save states of the whiteboard. Users can eventually navigate through different whiteboard states and eventually load a state to continue working at any previous step. This property is also useful for analyzing the progress of the creativity process and helps debriefing.

Stormboard [4] is a web brainstorming and real-time collaboration application. It allows generating ideas using the mouse and the keyboard in form of text, image, documents and sketches on different devices. Once a storm created, other individuals can be easily invited to participate. All ideas can be commented allowing the team to discuss and refine ideas. Each participant has a number of votes that can be fully or partially used to designate his favorite ideas. Stormboard has the advantage to provide great models of templates. It also allows bringing out advanced statistical reports taking into account the position of the sticky notes on the templates. However, in the current version of Stormboard, sticky note cannot be linked or clustered.

\section{EFFECTIVE FACILITATION-ORIENTED FUNCTIONS}

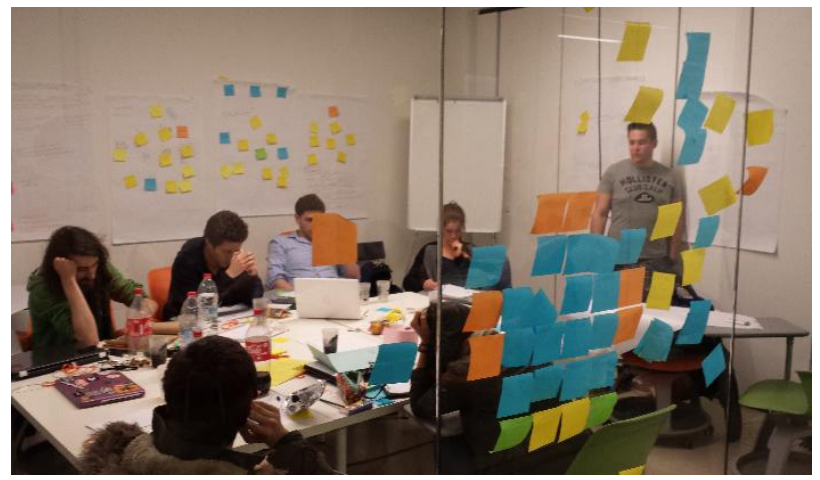

Figure 1. Paper-based creativity sessions

Digitalization of creativity session give groups creativity several advantages over traditional (Figure 1), paperbased meeting such as:

- Easy generation and capture of ideas,

- Collaboration intra-distributed groups across space and time,

- Collaboration in real time,

- Flexible structuration and organization, Automatic recording of the different stages of the session,

- Conducting a focus: selection, zoom, grouping,

- Voting ideas and export statistical reports.
On the other hand, previous comparative studies have shown that providing facilitation advice to group members can enhance the group interaction and improve derived results [14]. Furthermore, researchers suggest two possible complimentary manners to improve the group interactions: the effectiveness of the group facilitation and the use of appropriate technology to support groups [12, 7].

Nevertheless, already existing software we presented in the previous section do not distinguish explicitly the role of the facilitator of the creativity session from others participants. Indeed, all participants get to actively participate and have all access rights for creating, editing, organizing and evaluating notes during the session. This explains the difficulty of the professional facilitators to use this kind of software; it is clearly difficult for them to manage the creativity session, in the same manner as they do in the paper-based sessions, in several stages by progressively activating the participants' accessibility to certain functions.

According to these findings and drawing on concrete experiences of practitioners, we have identified a set of potential features that have to be taken into account to build an embedded facilitation in digital creativity sessions.

\section{Explicitly separate the role of the facilitator from other participants}

Two kinds of users have to be distinguished from each other in the interface:

- The facilitator: he has access to all functions and can enable or disable at any time users access to any function.

- The other participants: they can access to the enabled functions and interact according to the directives of the facilitator.

\section{Configurable and flexible session settings}

The facilitator has to be able to configure the session settings according to creative process that will adopt. Indeed, he should be able to choose the:

- number subgroups of participants: the facilitator can eventually divide the participants in subgroups.

- number of the involved whiteboards: the facilitator enters the groups' participants and can load a background template.

- number of the processing steps: for each step, the facilitator chooses the options/functions accessible by the participants.

\section{Configurable and flexible processing steps settings}

For each step, the facilitator chooses, through a checkbox, functions to be activated, principally:

\section{Mode of interaction}

- Individual: participants can only create ideas on their dispositive but they cannot see ideas the group members had contributed. The animator sees ideas happen on his workspace and can 
bookmark valuable ideas.

- Collaborative: The idea space is shared and visible for all participants. All their actions are directly applied on the shared space.

\section{Sticky-notes options}

- Generating links between sticky notes to create UPSTREAM and DOWNSTREAM concept

- Assessment functions that can by a:

○ simple number voting function (configure the number max of votes by sticky note),

- comment function,

- sdvanced voting function: originality, feasibility...The facilitator can add new voting criteria.

\section{CONCLUSION}

In this work we remind the importance of the facilitator role for assisting the group to be effective and reproduce relevant results. Despite the potential benefits of the group-facilitation, we were noted that current collaborative applications for creativity do not taking into account the specific role of the facilitator. We believe that implementing the facilitator style into digital applications for creativity session has a great potential for improving group interaction and outcomes. It may furthermore encouraging practitioners and professional consultants to adopt these applications and moving beyond classical paper-based approaches.

Building on this outcome, we introduced some guidelines to build effective facilitation-oriented functions in digital creativity sessions. The key element is to allow the facilitator to plan, organize and guide the creativity session as he usually does.

Our future work will focus on the design of a facilitatorparticipants model of interaction for creativity process in digital environment, specifying each mode of interaction and their relationship during the different stage of the creativity process.

\section{BIBLIOGRAPHIE}

[1] Evernote, Evernote Corporation, https://evernote.com, 2014.

[2] Liveminutes, LiveMinutes Inc,

http://liveminutes.com, 2011.

[3] Onnote, Microsoft Corporation,

https://www.onenote.com, 2013.

[4] Stormboard, Edistorm Inc.,

https://www.stormboard.com, 2013.

[5] A. BlumberG, R. T. G. Learning and change in groups. Penguin Books, 1976.

[6] ACKERMANN, F. Participants' perceptions on the role of facilitators using group decision support systems. Group Decision and Negotiation 5, 1 (1996), 93-112.
[7] Clawson, V., AND Bostrom, R. The importance of facilitator role behaviors in different face to face group support systems environments. In System Sciences, 1995. Proceedings of the Twenty-Eighth Hawaii International Conference on (Jan 1995), vol. 4, pp. 181-190 vol.4.

[8] EBERLE, R. Scamper: Games for Imagination Development. D.O.K. Publishers, 1971.

[9] EVErITT, K. M., KLEMMER, S. R., LEE, R., AND LANDAY, J. A. Two worlds apart: Bridging the gap between physical and virtual media for distributed design collaboration. In Proceedings of the SIGCHI Conference on Human Factors in Computing Systems (New York, NY, USA, 2003), CHI '03, ACM, pp. 553-560. [10] Gericke, L., GUMIENNY, R., AND MEINEL, C. Tele-board: Follow the traces of your design process history. In Design Thinking Research, H. Plattner, C. Meinel, and L. Leifer, Eds., Understanding Innovation. Springer Berlin Heidelberg, 2012, pp. 15-29. [11] GUMIENNY, R., GERICKE, L., WENZEL, M., AND MEINEL, C. Supporting creative collaboration in globally distributed companies. In Proceedings of the 2013 Conference on Computer Supported Cooperative Work (New York, NY, USA, 2013), CSCW '13, ACM, pp. 995-1007.

[12] Hamilton, E. E. The facilitation of organizational change: An empirical study of factors predicting change agents' effectiveness.

[13] Hilliges, O., Terrenghi, L., Boring, S., Kim, D., RiCHTER, H., AND BUTZ, A. Designing for collaborative creative problem solving. In Proceedings of the 6th ACM SIGCHI Conference on Creativity \&Amp; Cognition (New York, NY, USA, 2007), C\&C '07, ACM, pp. 137-146.

[14] JESSUP, L. M. Group facilitation and group support systems.

[15] KLEMMER, S. R., NEWMAN, M. W., FARRELL, R., BILEZIKJIAN, M., AND LANDAY, J. A. The designers' outpost: A tangible interface for collaborative web site design. ACM Press, pp. 1-10.

[16] OSBORN, A. Applied imagination; principles and procedures of creative problem-solving. Scribner, 1963.

[17] PARNES, S., AND HARDING, H. A source book for creative thinking. Scribner, 1962.

[18] PhILLIPS, LAWRENCE D.AND PHILlIPS, M. Faciliated work groups: Theory and practice. 533-549. [19] SCHWARZ, R. The skilled facilitator: practical wisdom for developing effective groups. The Jossey-Bass Management Series. Jossey-Bass Publishers, 1994. [20] SMITH, P. B. The t-group trainer: Group facilitator or prisoner of circumstance? Journal of Applied Behavioral Science 16, 1 (1980), 63-77. 